\title{
The problem and solution for town kindergarten fine art curriculum implementation
}

\author{
Yong xia $\mathrm{Li}^{1 \text {, a }}$, Jian Guang Zhang ${ }^{2, \mathrm{a}}$ and Ping Chen ${ }^{2, \mathrm{a}}$ \\ ${ }^{1}$ College of Education, Heng Shui University, Heng Shui, 053000, China \\ ${ }^{2}$ Department of Mathematics and Computer Science, Heng Shui UniversityHeng Shui, 053000, \\ China \\ a lynxzjg@tom.com
}

Keywords: Town, Kindergarten, Fine art, Curriculum Implementation

Abstract: The curriculum implementation is the important way to ensure kindergarten can carry out teaching and maintain quality of education. The main problem that constrains the quality of town kindergarten fine art curriculum implementation is that it has been marginalization and alienation. In this paper, we propose the solution for this main problem.

\section{Introduction}

With the promulgation of " Syllabus " and " guidelines " [1]., many researcher become to focus on the education quality issues of kindergarten. The significant factor that impacts kindergarten education quality is the kindergarten curriculum implementation. The curriculum implementation is the main channel and carrier for kindergarten teaching, quality and level promotion of this teaching. Kindergarten curriculum implementation can be introduced using two processes. First, it is the process that curriculum plan is putted into practice[2]. Second, it is process that the desired curriculum objectives and the child health development is realized, and curriculum idea is achieved. This process is made by different roles, which includes kindergarten teacher, children's own, children's parents and kindergarten[3].

The majority of Chinese kindergartens locate in towns. It is worth researching for current situation, many problems and effect promotion of the art curriculum implementation. To promote the quality of town kindergartens education, the key step is the investigation of town kindergarten art curriculum implementation. The pertinence suggestion about the improvement of town kindergarten curriculum implementation can be completed by interviewing many town kindergartens, deeply surveying and collecting many relative data.

\section{The problems of town kindergarten fine art curriculum implementation}

\section{A. The marginalization fine art curriculum implementation}

In the process of each field courses and theme events of town kindergarten, we find the most of kindergarten fine art curriculums have been replaced by language and math curriculums. In an interview of kindergarten teacher and leader, we can obtain the conclusion that the fine art curriculum is considered as unimportant curriculum or activity.

There are explicitly rules that, according to the activity category, the contents of kindergarten education can be divided into five aspects which includes health, society, science, language and arts, in "'Syllabus of kindergarten education' and " guidelines of children's learning and development ". But in the process of town kindergarten, the dominant role of the traditional subjects were regarded as language and math for a long time, and the fine art curriculum which was neglected by kindergarten teacher and leader, has been blank space for the town kindergarten curriculum implementation.

\section{B. There is alienation in the values-driven of kindergarten fine art curriculum}

The fine art curriculum implementation process has been carried out only in a small number of town kindergartens. The curriculum-designers think that child fine art curriculum is tightly scripted. The curriculum-executers consider the performance as the value and the target of curriculum implementation. The curriculum decision-makers described the main part as teacher and neglect the 
children's subjectivity. The values-driven of kindergarten curriculum implementation is tendentiousness which was held by organizer and executor during the process of kindergarten curriculum implementation. It also can be described as effective expectation and introduction start point of new curriculum implementation. Art activity has been considered as the emotion and creative activity in " Syllabus " and " guidelines " [1]. As a kindergarten teacher, the curriculum-executers follow books blindly and carry out fine art curriculum implementation without creativity. So the specialty of fine art curriculum implementation which includes creativity, pleasant development, feeling happy, perceiving, experiencing and creating beauty will become traditional, forced out and painful. This warp values-driven leads directly to neglect the quality of fine art curriculum implementation, influence children's appreciation and representation of fine art beauty.

\section{The contradiction between the abundant and scarce kindergarten fine art curriculum resource}

The investigated town kindergarten teacher and leader think that the development and utilization of fine art curriculum resource are impossible because two reasons. The first reason is that the most of fine art curriculum resource is the textbooks which are published by province. The other reason is that the economy, environment and condition of town are relatively backward, and there is no park, museum and theatre of city in town. There are the binary contradictions between the city and town, the education policy, Investment funds and the content and resource of kindergarten curriculum tend to city as the center. But the town civilization and culture play more and more important role for education development. As the kindergarten fine art curriculum resource, there are abundant natural resources which include plants, insects, animals, hills, waters, rocks, and soil, folk culture resource which include folk song folk rhyme, folk art craft and folk garments. The most of this resource, which can be touched by town kindergarten, are the life experience of kindergarten fine art curriculum, but it is neglected by teachers.

\section{The lacking ability and motivation of kindergarten fine art curriculum implementing the subject}

Through this survey, the curriculum implementation ability and motivation of town kindergarten teacher are worrisome. In a small number of town kindergartens which carry out the fine art curriculum implementation, the Secondary and higher education teacher account for only 9.83\%, preschool education and fine arts major teachers are less than $10 \%$, the teachers with the kindergarten teacher certification are less than $8 \%$, the regular town kindergarten teachers are less than $7 \%$.The town kindergartens are tough conditions and low Welfare. In the investigated town kindergarten, the teachers are form the primary and middle school. In recent years, town kindergarten start to recruit preschool education major teacher, most of them are not regular staff. The kindergarten teacher lacks of motivation of course teaching research, course resource development and utilization and major development, because very mobile and Lack of motivative measure. By reviewing town kindergarten fine art curriculum, we find that kindergarten teacher only pay attention to the painting and handwork teaching, but neglect other fine art curriculum implementing contents which can promote the children to develop healthily and continuously. The mode including Demonstration, layered and teaching, organized and practice is main used in teaching by kindergarten teacher. But this mode neglects the exploratory for art beauty, initiative for researching, reduce the chance of free operation and practice, and restrict the Communication among children and teachers. So the kindergarten teacher should promote own accomplishment and course teaching of fine art curriculum implementing.

\section{The research for the solution of town kindergarten fine art curriculum implementation problems}

\section{A. Recovering the standard kindergarten fine art curriculum implementing}

The purpose of The kindergarten art curriculum implementation is to promote the child's development. This purpose contributes to help kindergarten teachers think deeply the meaning and value of art curriculum, well-design the curriculum implementation scheme. This purpose contributes to help child feel, enjoy and explore beauty. 
Firstly, the consciousness is the fountainhead of action. For the marginalization and the values-driven missing of town kindergarten fine art curriculum implementation, town kindergarten leaders, teachers and children's parents should ensure the correct understanding of kindergarten fine art curriculum and enhance the learning for the regulatory framework of kindergarten education. These requirements can be completed by participating the national training plan, independent study and teaching and researching activity. Secondly, town kindergarten leaders, teachers need understanding the content in " Syllabus " and " guidelines ", serious reflection and actively practice. Action is true meaning. The standard kindergarten fine art curriculum implementing can be recovered by reflection, adjusting and reaction.

\section{B. Giving full play to the value of kindergarten fine art curriculum implementing the subject.}

The teacher and child is the subject of fine art curriculum implementing. The initiative and participation degree of double subject directly influence on the Effect and quality of fine art curriculum implementing. Firstly, the own consciousness and autonomy of town kindergarten teacher should be promoted. The kindergarten teacher bears the burden of realizing the target of child development. The direction and effect of curriculum implementing are influenced by the kindergarten teacher's Understanding the values-driven of art curriculum. The curriculum implementing is the process. From this process, Teacher can give Initiative and creativity back to child, grow up and experience teaching happy [4]. The kindergarten teacher can creatively Design and implement the fine art curriculum which is suitable for development of Local kindergarten and requirement for local child by combining the own comprehension of art curriculum, requirement of child physical and mental development and the existing experience of child. Secondly, we must give play to the effect of child in fine art curriculum implementing. The child is the implemented object of fine art curriculum, but if child don't participate the curriculum implementing, we have no way to finish the complete curriculum implementing, evaluate the effect of curriculum implementing. So the status and value of curriculum implementing the subject should be actively gave play to in town kindergarten fine art curriculum implementing. The initiative of participating curriculum should be motivated, the target of Appreciate and performance ability development of art beauty of teacher and child should be .promoted.

\section{C. active development and utilization for abundant local fine arts curriculum resources}

The curriculum resources are basic components and guarantees of curriculum implementing. The level of curriculum implementing can be decided by richness, Development and application of curriculum resources[5]. Firstly, To meet the requirement of "Syllabus " and " guidelines ", the necessary basic resources of town kindergarten fine art curriculum Implementing should be provided by increasing policy guarantee and investment of nation, local government and kindergarten. Secondly, to promote the consciousness and ability of independent development of local curriculum resources, town kindergarten leader, teacher, child and parents should be encouraged to explore the usable fine arts curriculum resources of local region, local kindergarten and class.

\section{Establishing the scientific Supervision and incentive mechanism of kindergarten curriculum implementing}

The scientific Supervision and incentive mechanism of kindergarten curriculum implementing is the important promotion measures of the Development and reform of kindergarten curriculum. The thorough Supervision and incentive mechanism of kindergarten curriculum implementing includes kindergarten leader, teacher, curriculum implementation process, child and parents. The contents which mechanism involve, follow as: The deliberation of fine arts curriculum, the supervision of course progress, the examination of teacher Qualifications, evaluation of teacher-student interaction, implementation effect and Development and utilization of curriculum resources, the incentive method of course reform and curriculum resource development. To ensure the quality of town kindergarten fine art curriculum implementing, we must establish the scientific Supervision and incentive mechanism of kindergarten curriculum implementing. 


\section{Conclusion}

The main problem of basic course reform and kindergarten educational reform is curriculum implementation, which has significance meaning for kindergarten education and child's development, and gives expression to the educational concept, education view of kindergarten education. Because of the artistic characteristics, the art curriculum as the one curriculum of the kindergarten art domain attracts many researchers' attention. The town kindergarten is the subject of the kindergarten system. The researchers consider the town kindergarten as the research object and the town kindergarten art curriculum implementation as research topic. In the survey, the problems of the kindergarten art curriculum implementation include: implementation marginalization, value orientation alienation, curriculum resource contradiction and less ability or motivation. In this paper, we deep analysis above problems and propose the feasible comments and suggestions, which include restoring the purpose of the kindergarten art curriculum implementation, development and utilization the local art curriculum resource and establishing the supervision and incentive mechanism of the kindergarten art curriculum implementation.In this paper, we propose new research perspective, object and method. We replace the city kindergarten by town kindergarten as the researching attention. We consider the real state of the kindergarten art curriculum implementation as the researching object. We pay our attention on the child's artistry development.

In the future, we can pay our researching attention on the evaluation system of the town kindergarten art curriculum implementation, the difference quality of kindergarten art education between the city and town, and the complete curriculum implementation system.

\section{Acknowledgment}

This work was supported by the China Hebei province social science foundation the research for the problem and solution of town kindergarten fine art curriculum implementation (No.HB11JY005) and Hengshui University College project the investigation for Hengshui City confinement nurse Working conditions (No.2013065).

\section{References}

[1] Xu Li, The Value Orientation of the Implemanting New Curriculum in Guangxi Kingdergartens, 2011, 4 (1) : 60-65.

[2] Ma YunPeng, Curriculum and teaching theory[M], The central radio and television university press, 2005:64-65

[3] Shi FangLiang, Curriculum theory - curriculum, principles and problems[M], Education science press, 1996:128.

[4] Li ChunLi, Teachers and children in the kindergarten curriculum implementation [J].Journal of Educational Development. 2012, (6) : 17-20.

[5].Wu Gangping, curriculum resources theory[J], Educational Research, 2012 （9） : 59. 